\title{
ANALISIS VALIDASI KEDALAMAN GERUSAN AKIBAT ALIRAN DITIKUNGAN SUNGAI DENGAN METODE RIPLEY
}

\author{
MAIZIR \\ Institut Teknologi Padang
}

\begin{abstract}
The phenomenon of flow passing through bends in the river is very interesting to observe. In large enough flows, it can generally cause the outer wall of the river bend to slide and the occurrence of scouring/erosion at the bottom of the river, while in the inner bend there is sediment deposition. In rivers whose walls consist of stone pairs with soil riverbeds, scouring will occur at the riverbed. In this study, observations were made on the results of the analysis of the scour depth at the outer river bend with the Ripley formula, and compared the results of the measurement of the scour cross section that occurred at the outer river bend. The Ripley formula is usually used to determine the scour that occurs at the outer river bend in the field. The location of the observation was carried out at the bend of the Batang Kuranji river under the Siteba bridge. The study began by measuring the situation of the river crosssection in the field, determining the annual flood discharge based on rainfall data to determine the magnitude and depth of the flood water level, calibrating the flood discharge data with field conditions, analyzing the configuration of the cross-section of the river based on the Ripley formula and comparing it with the measurement results. field. In general, it can be concluded that the scour depth calculated by the Ripley formula is proportional to the scour depth measured in the field.
\end{abstract}

Keywords: river bend, scour depth.

Abstrak: Fenomena aliran yang melewati tikungan di sungai sangat menarik untuk diamati. Pada aliran yang cukup besar umumnya dapat menyebabkan dinding ditikungan sungai sebelah luar longsor dan terjadinya gerusan/erosi pada dasar sungainya, sementara ditikungan sebelah dalam terjadi endapan sedimen. Pada sungai yang dindingnya terdiri dari pasangan batu dengan dasar sungai tanah, gerusan akan terjadi pada dasar sungai. Dalam penelitian ini dilakukan pengamatan terhadap hasil analisis kedalaman gerusan ditikungan sungai sebelah luar dengan rumus Ripley, dan membandingkannya hasil pengukuran penampang gerusan yang terjadi ditikungan sungai sebelah luar. Rumus Ripley biasanya digunakan untuk menentukan dengan gerusan yang terjadi ditikungan sungai sebelah luar di lapangan. Lokasi pengamatan dilakukan ditikungan sungai batang Kuranji dibawah jembatan Siteba. Penelitian dimulai dengan melakukan pengukuran situasi trase dan penampang sungai di lapangan, menentukan debit banjir tahunan berdasarkan data curah hujan untuk mengetahui besar dan kedalaman muka air banjir, mengkalibrasi data debit banjir dengan kondisi lapangan, menganalisis konvigurasi penampang sungai berdasarkan rumus Ripley dan membandingkannya dengan hasil pengukuran lapangan. Secara umum dapat ditarik kesimpulan bahwa kedalaman gerusan yang dihitung dengan rumus Ripley sebanding dengan kedalaman gerusan hasil pengukuran di lapangan.Dan rekomendasi Chow bahwa untuk keperluan praktis, pemakaian rumus Ripley dalam merencanakan penampang lintang di tikungan sungai memberikan hasil yang memuaskan, terbukti benar.

Kata Kunci: tikungan sungai, kedalaman gerusan. 


\section{A. Pendahuluan}

Sungai Batang Kuranji adalah salah satu sungai yang mengalir di tengan kota Padang. Hulunya berada di kawasan Batu Busuk, dan bahagan hilirnya mengalir melalui kawasan Siteba dan bermuara di pantai Ulak Karang. Trase sungai di bahagian hilir ini sudah dinormalisasi pada tahun 1998. Dinding saluran kiri kanan dibuat dengan konstruksi pasangan batu mulai dari intek PDAM sampai ke muara. Pada trase sungai yang sudah dinormalisasi ini, yaitu dibagian hilir dari jembatan Siteba terdapat tikungan sungai dengan sudut sebesar $80^{\circ}$.

Dari pengamatan visual kondisi aliran ditikungan sungai ini pada waktu banjir, terlihat aliran seolah-olah mengumpul pada bagian luar tikungan sungai, sementara tikungan sebelah dalam seolah-olah ditinggalkan oleh aliran tersebut. Aliran ini biasanya akan menyebabkan rusaknya dinding dan dasar sungai pada bagian luar tikungan, sementara ditikungan sebelah dalam terjadi endapan. Pada bagian dalam dari tikungan ini terdapat endapan sedimen yang setiap tahun dikeruk oleh Dinas PSDA (Balai Wilayah Sungai) dan dikembalikan pada kondisi awalnya, yang rata-rata dilakukan sebelum musim hujan. Pada tikungan sebelah luar terjadi gerusan pada dasar sungai. sementara bagian yang tergerus tersebut dibiarkan. Pengerukan terakhir dilakukan pada bulan April 2018. Dari hasil pengamatan secara visual, kelihatannya kedalaman gerusan ditikungan tersebut sudah mencapai kondisinya yang stabil.

Dari hasil pengamatan, bahwa pada setiap habis musim hujan endapan tersebut kembali lagi pada posisi semula, yaitu pada bagian tikungan sebelah dalam terjadi endapan. Begitu juga pada bagian tikungan sebelah luar terdapat palung pada dasar sungai.

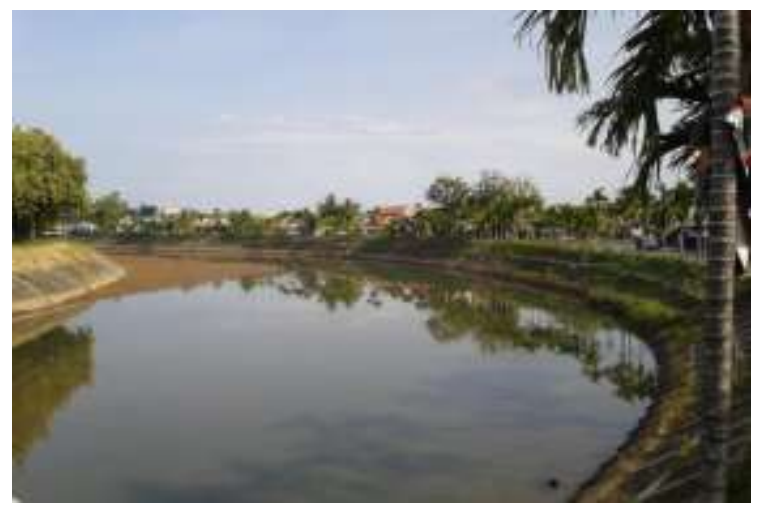

Gambar 1. Situasi lokasi tikungan sungai yang diamati

Dalam perencanaan saluran atau sungai, pada umumnya tidak diinginkan adanya suatu tikungan atau belokan pada trase alirannya. Kasus aliran ditikungan sungai sudah dibahas dan diteliti oleh banyak ahli, salah satunya adalah Ripley (Chow, 1985). Masalahnya adalah apakah persamaan Ripley memenuhi dimensi penampang sungai yang terjadi di tikungan tersebut. Dalam penelitiannya, Ripley menghasilkan persamaan konvigurasi palung sungai yang terjadi akibat aliran ditikungan sungai. Tujuan penelitian ini dengan maksud untuk mengetahui apakah konvigurasi penampang sungai yang terjadi di tikungan tersebut sesuai dengan konvigurasi penampang yang dianalisis dengan rumus Ripley

\section{B. Metodologi penelitian}

Pelaksanaan penelitian adalah dengan mengukur penampang tikungan sungai Batang Kuranji. Hasil pengukuran penampang tersebut dibandingkan dengan hasil hitungan penampang menurut rumus Rypley. Dalam hal ini yang dianalisis adalah penampang aliran setelah adanya endapan sedimen yang terjadi. 


\section{Hasil dan Pembahasan.}

\section{Pengukuran penampang sungai}

Pengukuran penampang sungai dilakukan dengan pesawat ukut Theodolit Nicon NT2D. Hasil pengukuran penampang sungai pada as tikungan.

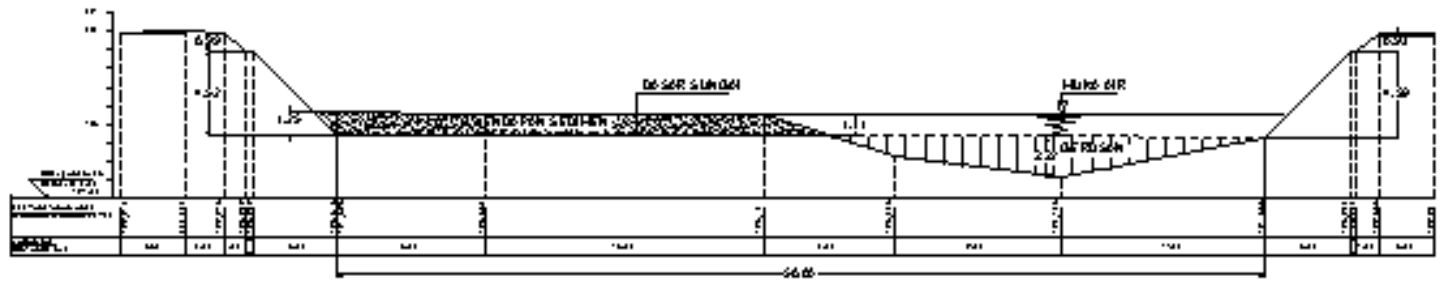

Gambar 2. Profil melintang tikungan Sungai Batang Kuranji

Dari pengukuran lapangan diperoleh hasil, yaitu lebar dasar sungai 50,00 m, sisi tebing (sisi tanggul) dari pasangan batu dengan kedalaman rata-rata 4,50 m. Pada kemiringan sisi $1: 1$, sisi tanggul bagian atas dari timbunan tanah rata-rata sedalam $1,00 \mathrm{~m}$ dasar sungai di tikungan bagian dalam terdapat endapan sedimen dengan ketebalan rata-rata $1,10 \mathrm{~m}$, dan di tikungan bagian luar terdapat gerusan (erosi) pada dasar sungai dengan kedalaman terbesar 2,22 m, kemiringan memanjang sungai rata-rata 0,0021. Radius tikungan luar 300,00 m.

\section{Analisis debit banjir}

Selanjutnya untuk analisis debit banjir tahunan sebaiknya menggunakan data debit. Karena data debit dari sungai Batang Kuranji tidak ada, maka analisis debit banjir tahunan menggunakan data hujan. Ada 2 stasiun hujan yang representatif dan terdapat dalam daerah tangkapan hujan (catchment area), yaitu stasiun pencatatan hujan Batu Busuk di kawasan hulu sungai, dan stasiun pencatatan hujan Gunung Nago di bagian tengah. (gambar 4). Dari kedua stasiun hujan tersebut diperoleh data pencatatan hujan masing-masing selama 25 tahun (1986 s/d 2010). Sebaran data curah hujan harian maksimum dari kedua stasiun pencatatan hujan tersebut dapat dilihat pada gambar 4

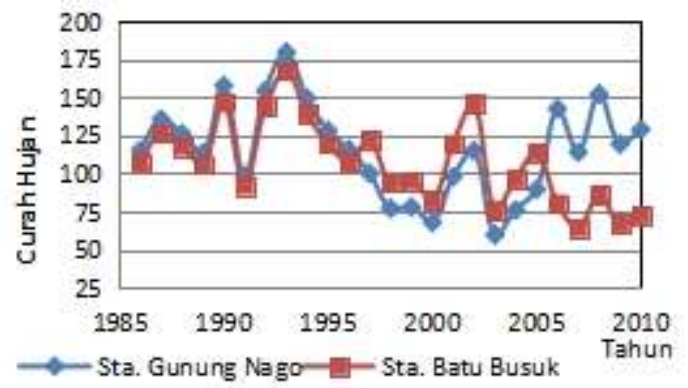

Gambar 3. Grafik sebaran hujan Sta. Gunung Nago dan Sta. Batu Busuk

Dari tahun 1986 s/d 1997 sebaran hujan pada kedua stasiun terlihat seragam dan merata, dan dari tahun 1998 s/d 2010 sangat bervariasi. Tahun 1998 s/d 2000 curah hujannya sedikit sekali (tahun kering). Oleh sebab itu untuk perhitungan debit banjir, digunakan data hujan kedua stasiun dari tahun 1986 s/d 1998. (13 tahun). Karena letak kedua stasiun berdekatan, terpisah dengan jarak $+3,50 \mathrm{~km}$. maka curah hujan rencana dapat dihitung berdasarkan curah hujan rata-rata kedua stasiun.

Hasil analisis dengan metode Iway dan distribusi Gumbel, didapat sebagai berikut :

Tabel 1. Curah Hujan Harian Maksimum Rencana (mm)

\begin{tabular}{|c|c|}
\hline $\begin{array}{c}\text { Periode } \\
\text { Ulang }\end{array}$ & Curah Hujan Harian \\
Maksimum Rencana $(\mathrm{mm})$ \\
\hline
\end{tabular}




\begin{tabular}{|c|c|c|}
\hline (tahun) & Iway & Gumbel \\
\hline 3 & 131.71 & 133.68 \\
\hline 5 & 146.74 & 147.18 \\
\hline 10 & 166.99 & 164.14 \\
\hline 50 & 216.50 & 201.48 \\
\cline { 2 - 3 } 100 & 239.52 & 217.26 \\
\hline
\end{tabular}

Hasil analisis kedua metode hampir sama besar (identik). Curah hujan tahunan rencana yang akan digunakan adalah curah hujan dengan periode ulang 3 tahun, yaitu $132 \mathrm{~mm}$

Tabel 2. Hujan harian maksimum rencana $\left(\overline{\mathrm{R}}_{\text {mak }}\right)$
\begin{tabular}{|l|c|}
\hline $\begin{array}{l}\text { Metode } \\
\text { analisis }\end{array}$ & Curah hujan rencana \\
\hline Iway $\left(\mathrm{R}_{3}\right)$ & 131.7 \\
\hline Gumbel $\left(\mathrm{R}_{3}\right)$ & 133.7 \\
\hline
\end{tabular}

Dari peta topografi skala $1: 50.000$, diperoleh luas daerah tangkapan aliran $72.60 \mathrm{~km}^{2}$.

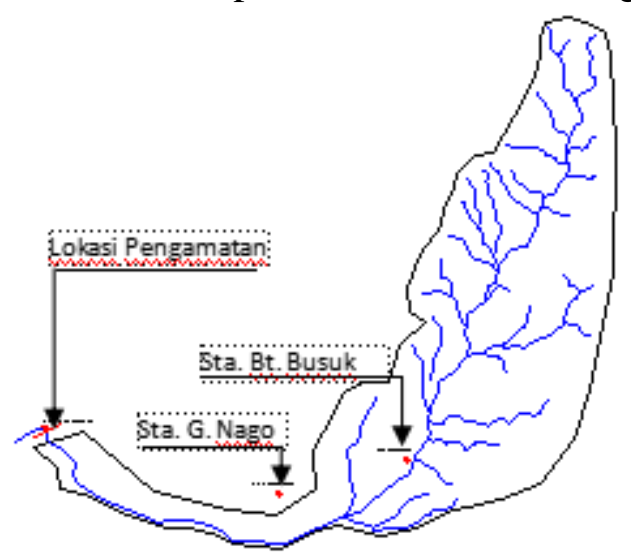

Gambar 4. Daerah Tangkapan Aliran Sungai Batang Kuranji

Debit banjir tahunan dihitung dengan metode Rational.

$$
\mathrm{Q}=\frac{\mathrm{f} \cdot \mathrm{r} \cdot \mathrm{A}}{3,6}
$$

$r=\frac{R}{24}\left(\frac{24}{t}\right)^{2 / 3}$

$t=0,0139 \cdot L^{1,6} \cdot H^{-0,6}$

$\mathrm{f}=$ koeffisien pengaliran, $\mathrm{r}=$ intensitas hujan, $\mathrm{A}=$ luas daerah tangkapan hujan (catchment area), waktu konsentrasi, $\mathrm{L}=$ panjang sungai, dan $\mathrm{H}=$ beda elevasi hulu dan hilir sungai.

Mengingat daerah aliran sungai bagian hulu umumnya merupakan sawah dan kebun, dan dibagian hilir merupakan daerah pemukiman, maka koeffisien $\mathrm{f}$ ditetapkan sebesar 0,60. Dengan metode Rational diperoleh debit banjir tahunan $301,69 \mathrm{~m}^{3} /$ detik.

\section{Analisis penampang aliran.}

Langkah selanjutnya adalah menghitung kedalaman aliran akibat debit banjir. 
Lebar sungai $(\mathrm{b})=50,00 \mathrm{~m}$, kemiringan sisi $(\mathrm{m}) 1: 1$, kemiringan memanjang sungai rata-rata $(\mathrm{I})=0,0021$.

Kecepatan aliran dihitung dengan rumus Manning :

$\mathrm{V}=\frac{1}{\mathrm{n}} \mathrm{R}^{2 / 3} \mathrm{I}^{1 / 2}$

$\mathrm{n}=$ koeffisien Manning.

Untuk saluran dengan dinding pasangan batu dan dasar tanah endapan berbutir lepas, diambil $n=0,022$.

$\mathrm{R}=\frac{(\mathrm{b}+\mathrm{m} \cdot \mathrm{y}) \mathrm{y}}{\mathrm{b}+2 \mathrm{y} \sqrt{1+\mathrm{m}^{2}}}$

$\mathrm{R}=$ jari-jari hidrolis penampang dan $\mathrm{y}=$ kedalaman aliran.

Penampang sungai pada tikungan ini bervariasi pola dasarnya mulai dari awal tikungan sampai akhir tikungan, maka yang diambil sebagai sampel adalah bagian penampang pada as tikungan. Untuk debit aliran 301,69 $\mathrm{m}^{3} /$ detik, didapat kedalaman aliran $(\mathrm{y})=1,90 \mathrm{~m}$. Kedalaman aliran ini identik dengan bekas-bekas banjir yang terdapat pada dinding sungai. Jadi kedalaman banjir tahunan sebesar 1,90 m ini dapat dinyatakan memenuhi, dan angka ini akan digunakan untuk menentukan kedalaman gerusan yang terjadi pada tikungan sungai.

Sifat aliran ditentukan dengan bilangan Froude $(\mathbf{F})$

$$
\mathbf{F}=\frac{\mathrm{V}}{\sqrt{\mathrm{gy}}}=
$$

Pada kedalaman y $=1,90 \mathrm{~m}$ kecepatan aliran $\mathrm{V}=3,06 \mathrm{~m} / \mathrm{det}$, diperoleh $\mathrm{F}=0.709<1$

Jadi aliran bersifat subkritis.

\section{Analisis penampang dengan rumus Ripley.}

Syarat pemakaian rumus Ripley adalah : aliran bersifat subkritis dan radius tikungan $\quad\left(r_{0}>40 \sqrt{A}\right)$. Kedua syarat tersebut terpenuhi. Penampang sungai hasil pengukuran ini selanjutnya dibandingkan dengan penampang yang dihasilkan menurut rumus Ripley. Hasil hitungan dengan rumus Ripley untuk kedalaman aliran $(y)=1,90$ m adalah sebagai berikut :

Tabel 3. Hasil hitungan kedalaman gerusan menurut rumus Ripley

\begin{tabular}{|c|c|c|c|c|}
\hline $\mathrm{Rc}(\mathrm{m})$ & $\mathrm{T}(\mathrm{m})$ & $\mathrm{D}(\mathrm{m})$ & $\mathrm{x}(\mathrm{m})$ & $\mathrm{y}(\mathrm{m})$ \\
\hline 300 & 54.00 & 1.926 & -25.00 & -0.261 \\
& & & -20.00 & -0.599 \\
& & & -15.00 & -0.627 \\
& & & -10.00 & -0.459 \\
& & & -5.00 & -0.178 \\
& & & 2.50 & 0.320 \\
& & & 0.00 & 0.154 \\
& & & 2.50 & 0.320 \\
& & & 7.00 & 0.476 \\
& & & 10.00 & 0.616 \\
& & & 12.50 & 0.731 \\
& & & &
\end{tabular}




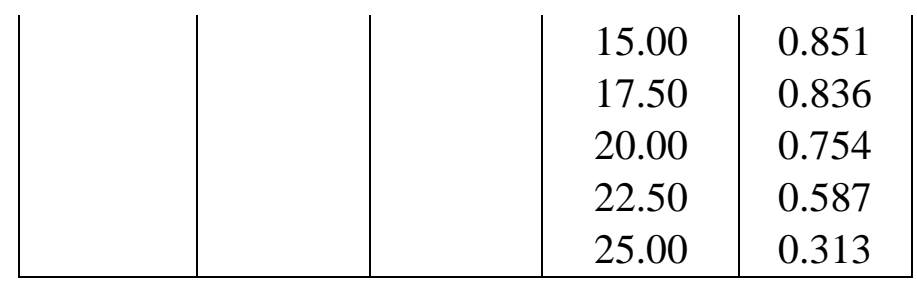

Perbandingan hasil ploting penampang gerusan yang dihitung dengan rumus Ripley pada dan gambar penampang sungai hasil pengukuran lapangan dapat dilihat gambar 6 berikut :

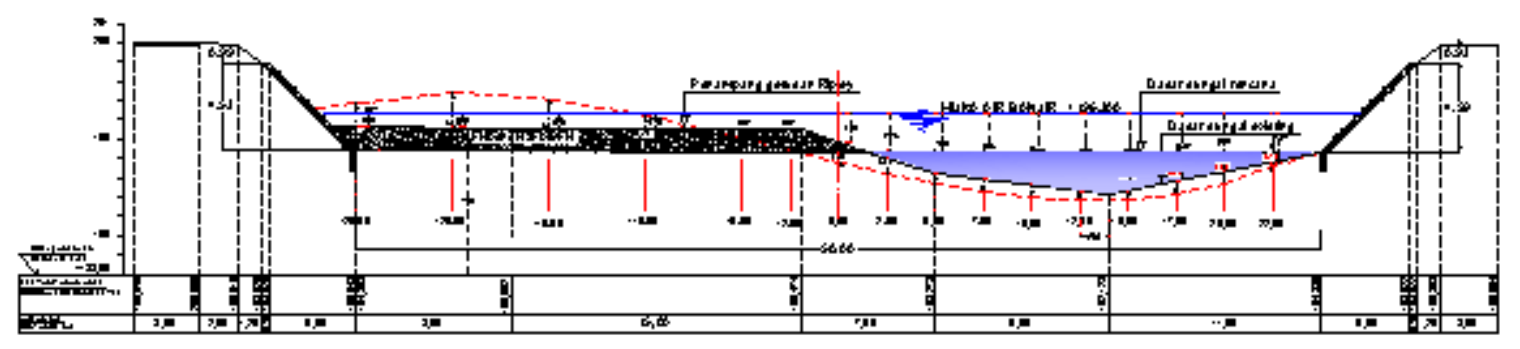

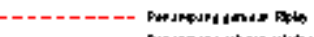

Gambar 5. Ploting perbandingan penampang gerusan hasil hitungan dengan rumus Ripley dan keadaan lapangan:

Perbandingan kedua penampang tersebut ditampilkan dalam bentuk grafik sebagai berikut :

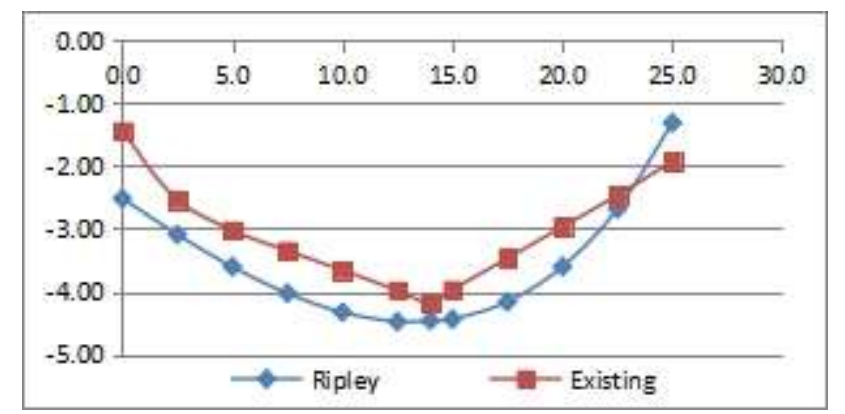

Gambar 6. Grafik perbandingan kedalaman gerusan menurut Ripley dengan penampang existing

\section{Penutup}

Dari hasil ploting kedalaman gerusan menurut hasil hitungan Ripley pada penampang sungai hasil pengukuran lapangan ternyata lebih luas dan lebih dalam dibanding gerusan yang sebenarnya terjadi pada penampang existing. Gerusan yang terdalam terjadi pada posisi yang sama dengan penampang existing. Gerusan menurut hasil hitungan Ripley lebih dalam 0,28 m (6,8 \%) dari gerusan yang sebenarnya terjadi pada penampang existing. Secara umum dapat ditarik kesimpulan bahwa kedalaman gerusan yang dihitung dengan rumus Ripley sesuai dengan kondisi lapangan. Kesimpulan ini tentunya masih bersifat sementara, karena penelitian ini baru dilakukan pada satu lokasi. Untuk menguji keandalan rumus tersebut masih perlu dilakukan penelitian sejenis pada berbagai lokasi dan keadaan sungai. Chow telah merekomendasikan bahwa untuk keperluan praktis pemakaian rumus Ripley dalam merencanakan penampang lintang di tikungan sungai, memberikan hasil yang memuaskan terbukti benar. 


\section{Daftar Pustaka :}

Muhammad Galib Ishak (2017); “Aliran Pada Belokan Saluran”. Untad Press, Palu. Djufri, Hasdaryatmin (2017); : "Studi Pengaruh Sudut Belokan Sungai Terhadap Volume Gerusan". Journal INTEK. April 2017, Volume 4 (1).

Sunaryo, Daoed, Darwizal, Laila Sari, Febby. (2010); "Pengaruh pemasangan krib pada saluran di tikungan $120^{\circ}$ ". Jurnal Rekayasa Sipil, Volume 6 No. 1, Februari 2010.

Dingman, S. Lawrence. (2009); "Fluvial Hydraulics", Published by Oxford University Press, Inc. 198 Madison Avenue, New York, New York 10016

Ukiman, Kodoatie, RY., Sriyana (2006); "Studi Konfigurasi Dasar Saluran Di Tikungan 90"\%. PILAR Volume 15, Nomor 1, April 2006

Greco, M., Carravetta., A, Della Morte, R. (Editor) (2004) ; "River Flow Volume 2", Proceedings Of The Second International Conference On Fluvial Hydraulics, 2325 June 2004, Napoli, Italy, Volume 2: ISBN 9058096882 (Print Edition) A.A.Balkema Publi-shers Leiden /London/New York/ Philadelphia/ Singapore Ven Te Chow, (1985); "Hidrolika Saluran Terbuka", Penerbit Erlangga, Jakarta 